\title{
Arguing with Images as Extended Cognition
}

\section{Cristián SANTibáñeZ}

\author{
Universidad Católica de la Santísima de Concepción \\ Alonso de Ribera 2850, \\ Concepción, Chile \\ csantibanez@ucsc.cl
}

\begin{abstract}
This paper proposes that images used within argumentative settings are examples of specific forms of extended and distributed cognition. Some insights are provided into the idea that the argumentative competence and activity is a manifestation of a more general human cognitive architecture. The paper first combines different perspectives in order to understand how the mind goes from accommodating its internal cognitive patterns to some regularities (environmental and cultural), to the ways in which the mind extends and distributes its cognitive resources. Then, this discussion is applied to the argumentative use of images by exemplifying both the internal accommodation and the extended and distributed cognitive functioning. In order to illustrate the former case (internal accommodation), the Toulminian argumentative diagram is proposed as an example of the tendency to organize events following a more basic cognitive pattern; and in order to illustrate the latter, a commercial campaign where image is used for argumentative purposes is analysed.
\end{abstract}

Résumé: On propose que les images utilisées dans des contextes d'argumentation soient des exemples de formes spécifiques de cognition étendue et distribuée. On avance quelques idées sur la notion que la compétence et l'activité argumentative sont la manifestation d'une architecture cognitive humaine plus générale. Cet article associe d'abord différentes perspectives afin de comprendre comment l'esprit passe de l'adaptation de ses schèmes cognitifs internes à certaines régularités (environnementales et culturelles), en passant par les manières par lesquelles l'esprit étend et distribue ses ressources cognitives. Ensuite, on discute de l'utilisation des images pour argumenter en illustrant à la fois l'accommodation interne et le fonctionnement cognitif étendu et distribué. Afin d'illustrer le premier cas (l'adaptation interne), on propose le diagramme argumentatif de Toulmin comme exemple de la tendance à organiser des événements selon un schème cognitif plus fondamental. Pour illustrer ce dernier point, on analyse une campagne commerciale dans laquelle l'image est utilisée à des fins argumentatives.

Keywords: cognition, diagrams, images, normativity, visual argumentation

(C) Cristián Santibáñez. Informal Logic, Vol. 38, No. 4 (2018), pp. 531-549. 


\section{Santibáñez}

\section{Introduction}

If it weren't for images, our jaws, mouth, and lips, would probably have a different physiognomy-monstrously big — as they would be the only means to communicate: A verbal alien (I know several of those!). If it weren't for images, we would not have had such an overwhelming variety in visual objects. The list of sublime accomplishments is long: art, architecture, transit signs, etc.

The variety of visual objects, signs, artifacts we have created and used throughout history manifest general cognitive strategies to deal with our environment - earlier than the documented evidence of the use of words (Corballis, 2018) - to represent and communicate actions, rules, desires, etc. For this simple reason-and others which will become apparent in this paper - it would be odd if the use of images were not part of a more particular competence such as the argumentative one embedded in, or part of, our communicative capacity.

In this paper I will contribute to the understanding of this use of image within an argumentative context by proposing that visuals with persuasive purposes can be seen, particularly, as extended repositories of arguments representing a collective point of view to be used in and for specific matters. By having these repositories, individuals reduce energy when creating and using inferences in a social context. At the same time, I propose that the argumentative uses of images that are available in the social and cultural sphere are manifestations of a distributed cognitive enterprise in which beliefs and points of views are located in different parts of a convergent effort. One of the main ideas of this work is that arguing with images is an intelligent strategy to build a niche, that is, the way humans adapt their surroundings to their necessities, which resembles the way the mind operates outside its biological boundaries to construct a niche in a broader way (Sterelny, 2012; Hutchins, 1995, 2005, 2008).

In order to develop and defend these ideas, I first describe some of the cognitive patterns from which the temporal-spatial reasoning processes stem (section 2). The core point of this section will be to show that even from a standard cognitive angle, what is called the computational view of the mind (see Dupuy, 2000), the mind 
assumes regularities from the environment to be incorporated into the representation that it creates and, by doing so, the majority of the images - such as maps, diagrams, figures - become external and extended resources that help the mind to process information. To exemplify this I will use the Toulminian model of argument.

In section 3, I will discuss how contemporary theory of argumentation has approached the problem of visual argumentation. In order to elaborate the discussion in this section, I will use a series of images that were part of political and commercial campaigns. My analysis will introduce comments to defend what I am proposing in this paper. And last, but not least, in the conclusion, I will reinforce the idea that visual argumentation can be seen as an extended and distributed manifestation of human cognition by adding and developing Huebner's concept of collective minds.

\section{Image: elemental cognitive processes}

Wittgenstein (2001) was a champion defending the idea that we have the know-how to follow a grammatical rule when we are confronted with and have to communicate, highly ambiguous and reversible images. According to Wittgenstein's philosophical intuitions, ${ }^{1}$ we follow a conceptual-logical formula to talk about perceptual experiences resembling known organizations. In the case of direct visual experiences, or if doubts just generate unnecessary perplexity, we observe how the cognitive system is already synchronized with meaningful input, adapted to the regularities that it perceives.

To a certain degree, part of the mainstream literature on the psychology of reasoning that has been devoted to these problems (Pohl, 2012), has confirmed those intuitions. When Gigerenzer (2007), to name one of the main researchers in this area, explains automatic inferences, he makes use of a series of optical illusions that, in reality, are the tip of the iceberg of our cognitive system's heuristically-organized processes. For example, see the following figure:

\footnotetext{
${ }^{1}$ Steven Patterson (2010) discusses in-depth Wittgenstein's approach to the visual to defend that it is not possible to ensure that images alone convey arguments.
}

(C) Cristián Santibáñez. Informal Logic, Vol. 38, No. 4 (2018), pp. 531-549. 


\section{Image 1}

Ramachandran's optical illusions

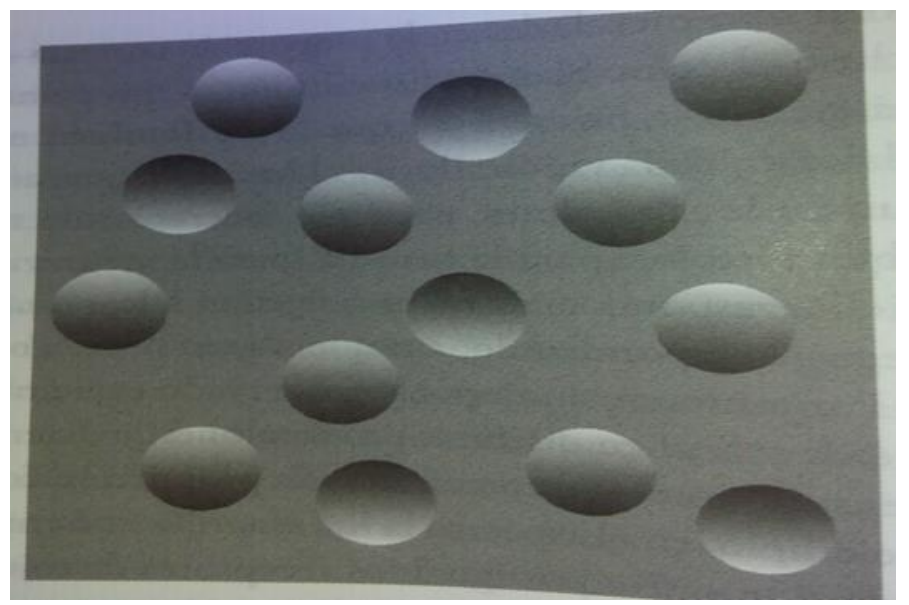

According to research in this field, our brain goes beyond the given information, beyond the information that the eye obtains. During this act, the brain derives meaning based on the structure of the surroundings or what it supposes is the structure, operating with heuristics. In image 1, the brain interprets some circumferences as concave (expanding inwards), and others convex (coming towards us). This occurs because our brain tends to see or interpret the images as if a spotlight is shining from above; but in fact, the brain just assumes the light comes from above, and that there is just one light source. These two structures, Gigerenzer (2007) asserts, are typical of humans' and mammals' evolutionary history since for them the sun and the moon were the only light sources.

Regularity imposes itself and takes possession of the brain. Now, and here the illusion is revealed, if we rotate the image 180 degrees, we will verify that the convex circles are concave, and vice versa. The general heuristic is: if the shadow is at the top, the dots sink into the surface; if the shadow is at the bottom, the dots are projected from the surface. Another example is the heuristic of recognition which states: if in a given situation an object is recog- 
nized, whereas another one is not, then it is inferred that the recognized object is more valuable (Pachur et al., 2012: 114).

In visuospatial-thinking research, as Hegarty and Stull (2012) call it, our visual experiences organize the understanding of a number of entities, objects, images, spaces, depending on the way in which we experience other objects. Thus, the experience with some entities generates some kind of rule of organization for levels and dimensions which, in general, are more difficult to apprehend.

One of the models that explains the recognition of objects is the view-based model. This model asserts that recognition functions by means of a dual dimensional projection or, in other words, a codified image from the observed point of view with a previous codification of a two-dimensional image that has been stored in the memory and recovered based on the common features. That is to say, this model emphasizes that the recognition of objects in space is influenced by the observer's experience with such objects, engraved in the memory, and those new or unfamiliar objects, which follow a similar process through which the engraved image is transformed so as to match with what is perceived. Regarding the most recent explanatory models, Hegarty and Stull (2012: 608) summarize the following:

"Graf (2010) proposes that recognition involves comparing the stimulus percept with the memory representations after Euclidian transformations (i.e., rotation, size, and displacement), whereas categorization involves additional non-Euclidian transformations that deform or morph the percept of an object to match a stored representation. In this light, the physical space of an object, the perceptual space encoded from the stimulus, and the representational space stored in memory might share a topological structure and object recognition and categorization might be based on common neural process."

This search for common grounds between known objects and perceived objects seems to be present in both the processes of object perception and imagination. The transformation that occurs, in terms of operations, goes from addition and subtractions to the decomposition of parts and elements. (These operations, by the way, are very similar to the process of the reconstruction of argu- 
ments as the pragma-dialectical theory in argumentation studies has always suggested (van Eemeren \& Grootendorst, 1992): suppression, addition, insertion of connectors and permutation of elements, and substitution, plus two general rules: logical minimum and pragmatic optimum).

Another dimension where visual and spatial representations play a key role is in deductive reasoning. For example, some researchers have stated that reasoning problems can be resolved by the creation of spatial mental models of such problems (Johnson-Laird, 1983), while others state that the fundamental underlying representations of reasoning are propositional (Rips, 1994). Even though the controversy continues, there is a consensus that spatial representations are definitely functional to reasoning. ${ }^{2}$ A paradigmatic case of the influence that spatial representations have in our understanding of more abstract relationships among elements is the use of maps, flows, graphs, and any kind of artifact drawn as an image that includes, supposedly, both the structure of a cognitive phenomenon and the functional relationships between its components.

An example in point is Toulmin's model of an argument (Groarke, 2009). Why this visual formula? This is the original diagram (Toulmin, 1958: 105):

Figure 1

A visual Toulmin's model of an argument

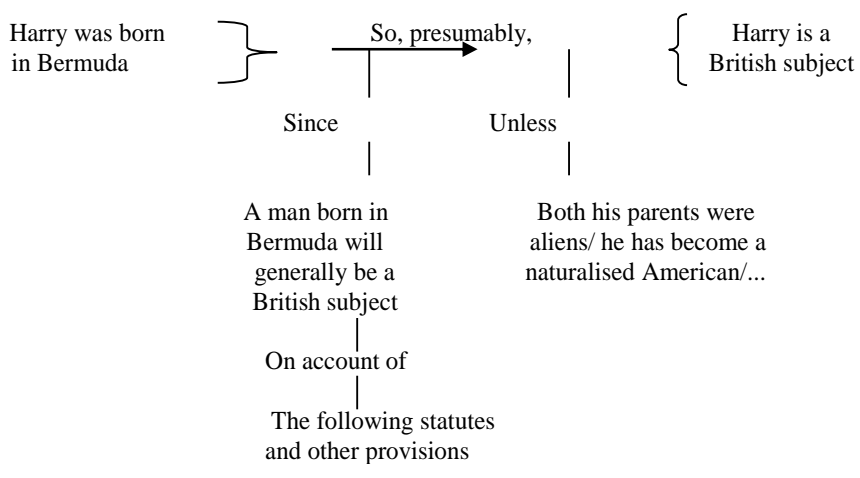

\footnotetext{
${ }^{2}$ Less evidence can be found on the role of spatial representations in conditional and categorical reasoning.
}

(C) Cristián Santibáñez. Informal Logic, Vol. 38, No. 4 (2018), pp. 531-549. 
For what reason does this diagram need to unfold in this way, visually? Do we better perceive the form of an argument, the functional relationships among its components, if we visualize it by means of this image? One of the responses from the cognitive studies of visual thinking (Tversky, 2011), argues that there are natural mappings between graphic forms and their meanings and between the spatial organization of these forms and their meanings. For instance, the lines are used to represent connections (as can be seen in Toulmin's model), circles to indicate cyclical processes, horizontality is mapped automatically as time (timeline), and the vertical lines are used to represent evaluative or hierarchical relations. In terms of my university, for example, the rector at the top, the teacher below, and in Toulmin's model the warrant is the continuation of the backing, the base of the structure.

As Malafouris (2013) has discussed in detail, material culturesuch as the artifacts we create to replace the functions of parts of our bodies - is the prototype evidence of an extended mind improving its performance by displaying its functions beyond its biological borders. As I will emphasize later, it is not only about that information being out there, namely in the Toulminian model the content of the argument reconstructed through its parts or categories (backing, warrant, and so on), but rather the cognitive process itself, that is, seeing that data supports a claim, and the claim gets its force from a warrant, etc. The visual organization of the argument is reconstructed, recovered and/or understood, from the regularities the mind has experienced from other linear relationships where one member of the chain gives support to the other one, even in cases where a loop or recursive manifestations can be obtained. Nonetheless, to be sure, this internal cognitive representation externally extended in maps, graphs, etc. corresponds to the view assumed by the first wave of cognitivism (Malafouris, 2013; Rupert, 2004).

Hegarty and Stull (2012: 621) remind us that:

Children show a strong preference for realistic representations, even when less realistic representations are more effective... when solving mathematical problems, the most successful students abstracted the essential information in the problem and represented it 
as a schematic diagram, whereas less successful students tried to imagine irrelevant visual aspects of the objects described in the problem

The literature names this type of visual unfolding of the cognates a metarepresentational ability. What the metarepresentational ability manifests is that the more realistic and simple the visual unfolding, the more it is preferred and used. This explains, perhaps, the success of Toulmin's model, and even of the pragma-dialectical representation of arguments, which by using a vertical representation, indeed, captures in part the normative dimension of the activity of arguing, namely, the force each member of the visual representation has over the other.

To further understand the functioning of images and graphs in inferential processes from a cognitive perspective, it is important to keep in mind the following ideas (see Hegarty \& Stull, 2012: 6212):

Models of graphics comprehension propose the following three component processes in understanding graphical displays. First, users must encode the visual features of the display... Next, they must map these onto the conceptual relationships that they convey (e.g., an upwardly sloping line show an increasing quantity). Finally, they need to relate these conceptual relationships to the referents of the graphs (e.g., an upwardly sloping line represents an increase in the value of some stock)... Understanding a graphic can also include making inferences from the information in the display, based on the individual's prior domain knowledge or other inference rules that can operate on the internal representation...Thus, graphics comprehension involves interaction between bottom-up perceptual processes of encoding information and top-down processes of applying graph schemas... and domain knowledge.

The seeming innocuousness of graphs (some lines arranged in an ascendant way and others in descendent ones, with attached numbers) hides, obviously, processes that are reinforced when images include color, interaction, movement, propositions, and dialogues. This is precisely the material an argumentative analysis has to deal with when trying to reconstruct its point(s) of view and reason(s). 


\section{Visual argumentation}

One of the main ideas of the hypothesis of extended cognition is the famous principle of parity (Clark \& Chalmers, 1998). The classic example consists of Otto and Inga's visit to the art museum in New York. They get lost on their way there, she consults her biological memory, and he, who suffers from Alzheimer's, consults the directions in his notebook. Both processes are functionally similar in enabling the dispositional beliefs regarding how to get to the museum.

As pointed out earlier, the Toulminian visual diagram of the argument can be seen as a functionally similar external resource and process to enable argumentative understanding and reconstruction. To have it (the diagram) out there helps to get (and grasp) the point of view communicated. The Lugano argumentative diagram and the pragma-dialectician argumentative design can be analyzed in the same way: ${ }^{3}$ external resources and processes to enable argumentative descriptions.

However, in which parallel sense to the Toulminian - or otherdiagram, is the following argumentative Image 2 a case of external and/or distributed cognition? Obviously, in this question there is a petitio principii, namely, that the image is in fact an argumentative one. But this latter question is, I believe uncontroversially, answered from, at least, a threefold perspective: 1) the intentional stance of the communicator, 2) the material information exposed in the advert, and 3) the type of context and dialogue in which the advert is inserted. Accordingly: 1) the communicator (the Israeli bookstore Steimatzky) is promoting and trying to sell to you (and

3 Metaphorically, the Lugano program's visual argument diagram could be seen as an inverted pyramid, beginning with, at one corner of the inverted pyramid, the "material" force of an endoxon, and in the other corner the "procedural" force of a maxim, both vertices being the starting point of an up-down argumentative reconstruction that finishes in the conclusion or point of view (for a detailed explanation of all the components of the Lugano program's argumentative scheme, see Rigotti \& Greco, 2010); the pragmadialectician's visual argument diagram, in turn, could be seen as a cascade, that is, the visual reconstruction of the point of view is at the top, which is then supported, in an updown visual orientation, by the reasons and these, subsequently, by the sub-reasons and so on.

(C) Cristián Santibáñez. Informal Logic, Vol. 38, No. 4 (2018), pp. 531-549. 
convincing you to buy) books, that is its target; 2) it contains explicitly the assertion "Read More", supported by the visual premises-more about this soon-, and 3) the persuasive type of dialogue and context mutually assumed by the communicator and potential viewers, the latter with the pragmatic knowledge that enables them to understand 1 and 2.

\section{Image 2}

"Read More" campaign by the Israeli bookstore Steimatzky

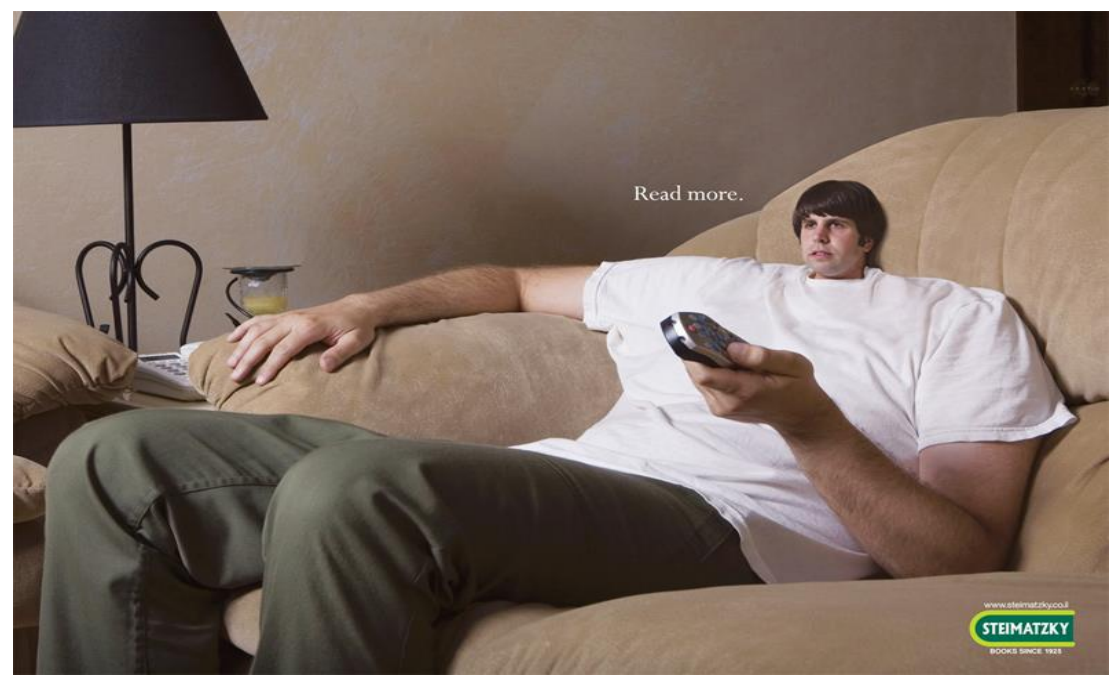

I think that the argumentative Image 2 is a case of distributed cognition for both the institutional-or collective-speaker (Steimatzky Bookstore) and the potential viewers. As a multimodal piece of communication (combining visuals, written text, colour, etc.), its persuasive force is in every element that constitutes its message, none is capable of conveying its persuasive force by itself. The written text "Read more" cannot reach its argumentative completeness on its own, without both the young man with the small head and big body and, the sign of the brand "Steimatzky Bookstore."

At this point it is worth remembering that the standard distributed cognition literature has observed (Holland \& Hutchins, 2009; Osbeck \& Nersessian, 2014) that all our activities are environmentally located, this is, are embodied, enculturated, and 
distributed across humans and artifacts. From this perspective, cognition is seen as an emergent property of interactions rather than a property limited or bounded inside an agent's brain.

What about the visual premises to support the written text "Read more"? Or asked differently, how to obtain verbal premises from the pictural or visual component? A possible answer is Marraud's (2016) use of both the ideas of the ostensive speech act and the Peircean analysis of exploiting inferential habits.

Another way to answer the question is by asking real audiences their understanding and argumentative reconstructions. This is the empirical approach, an alternative one to the analytical explanation. This is precisely what Kjeldsen (2015) has developed. Aware of how difficult it can be to define an argument theoretically, he simply suggests observing how audiences react to advertisements, commercials or political campaigns that convey argumentative messages through images; how those who receive a visual argument reconstruct it, interpret it, communicate it. To analyze this, he developed a series of focus groups (3, during 2014 in Norway), to "determine if the participants will perceive arguments in the advertisements, how they will perceive them, and from there explore the characteristics of visual argumentation" (2015: 109). After the participants observed Image 2, Kjeldsen used the following general opening question to start the conversation: What do you think when you see this picture? The answers, for example, of young Norwegians between 18 and 19 years old, were, among others, the following: "You lose intelligence when you watch television because your head gets smaller by doing so." Another one stated:

I think you start focusing more on television than on building your knowledge by reading. So, according to the advertisement, the head is going to get smaller and smaller if you watch television. And it will be bigger and bigger if you read books.

These are answers that we would all give, with different levels of sophistication. Kjeldsen's point is clear: people build or recover a lexicon (stupid, for example, based on a shrunken head) developing a pragmatic codification, namely, we evoke a lexicon to embed it in propositions that become arguments because these are already part of the contexts where such advertisements can be found. As

(c) Cristián Santibáñez. Informal Logic, Vol. 38, No. 4 (2018), pp. 531-549. 
Marraud (2016) has pointed out, this evoking shows in use what Peirce named inducing a belief, by means of exploiting the mental habit of producing inferences from content shared with others ("books make you more intelligent"), regardless of being true or false. The advertisements are read and coded in speech acts and operate, in the inferences that they promote, with the same conditions that assertions have (such as "read more").

In written reconstructions of arguments, we recover the connectors and conjunctions to join premises in the same way as we do in oral activities (surely as the Norwegians did it), where they are not explicitly expressed (connectors such as: thus, because, therefore, etc.). Cognitively, this must be similar to how the brain sees concave circumferences when it assumes that the light comes from above. That is, by default we automatically interpret that when an assertion is received, or another speech act with persuasive purposes with explicit or implicit elements that justify it, information or elements are added that make the set an organic whole. In this direction, both textual and visual argumentative understanding and reconstruction, automatic or strained, operate in the very same way: adding, or deleting if needed, connectors and other elements. Textual and visual argumentative activities are not exceptions of a broader human cognitive architecture.

\section{Final discussion: distributed and extended cognition revisited}

In this final section, I will explain my proposal by clarifying the extended-distributed cognition perspective, using the idea of collective minds to understand the use of visual argumentation.

As pointed out in the introduction, my proposal is to see visual argumentation as a specific form of the extended cognition hypothesis. In this perspective, I would also like to propose conceiving arguments materially embedded in shapes, colors, and textures, as depositories of collective minds (Huebner, 2015).

Recall (Malafouris, 2013) that the thesis of the extendeddistributed approach to the mind's cognition claims that an important part of thought, or whatever we want to use as a unit of 
analysis of mind and cognitive abilities, is outside of the brain. But, as part of the literature on cognition emphasizes (Hutchins, 1995, $2005,2008,2010)$, what is outside of the mind actually is not, or not necessarily, out of the mind. In order to study cognition, what happens between the mind, objects, people and environments, must be observed as well.

Cognition is spatially and temporarily situated, and thesespace and time - are cognitive artifacts, once they have been, precisely, built from those interactions (mind, objects, people, environments). The unit of analysis, thus, is the complete interaction of a body containing a mind. The essential point is that the mental machinery is an extended functional system that not only contains inner representational states but also involves the transformation and propagation of such states through external means. Because of that, and even if mental states could be internal in the traditional sense of intra-cranial representations, they can also be outside of the individual, such as tools, maps, graphs, that is, they are external to an individual's biological limits. Cognitive activity cannot be, in this way, reduced to inner neuronal activity. The classic example is that one cannot ask who is responsible for a ship's entry to the port, but rather how the necessary knowledge to do so has been activated and propagated between the people, the artifacts and the time involved in such an activity. According to Kirsh (1995, 1996), spatial coordinations are an important part of the functional architecture of any distributed cognitive system, in three dimensions: they contain and support selections, they contain and support perception, and they contain and support problem-solving. In the first dimension, space can be organized in such a way that it can constrain and even hide some possibilities for the purpose of reducing or simplifying the number of selections (hiding affordance), or vice versa, in an obvious way. Similarly, a specific organization of the space can draw the attention, or perception, toward certain entities to generate a particular action (the use of size and color are two ways that are usual and exemplary). And, unfolded from the two previous dimensions, problem-solving takes a specific orientation, limited, or directed by previous selections. 


\section{Santibáñez}

Given these types of elemental cognitive coordination to guide inferential processes, it seems that visual argumentation departs from, or is based on, them. For example, in Image 2 the depiction of a small head is a clear way to select a specific form of the use of space to guide perception and attention to activate a particular inferential process.

As the cognitive literature emphasizes (Holland \& Hutchins, 2009), and the analysis of Image 2 tries to demonstrate as well, it is not only that the mind externalizes information - similar to a symbolic external garage-, but the actual processing of information is externalized. Not only is the mental content outside, but the mental process (or part of it) is also. In the literature, this is called active externalism (Clark \& Chalmers, 1998; Clark, 2016). Pencil marks on a paper are not just registers of the contents of mental states, but rather their extensions. This way of understanding cognition tries to answer a twofold challenge: the limitations of human biology, hence the necessity to distribute our cognitive capacities and processes; and the fact that cognition does not have a location per se but organizes itself. That is, it is not between certain properties, but among the properties that it is activated.

In one of his most recent works, Clark (2016) associates the cognitive capacity with the need for, and getting used to, predicting. According to Clark, prediction is a distributed and incarnating strategy of our functional and hierarchical processes in different artifacts and entities deposited in the environment. ${ }^{4}$ I quote Clark's recent work because the author dedicates some specific comments to the idea of active inference when he is developing the idea of prediction and action in relation to motor control and the visual system (2016: $120 \mathrm{ff}$.). Of particular interest here is the way in which agents can reduce error in the prediction. In a nutshell, first, predictions that better align with the situation or incoming sensorial information are selected; and second, performing actions that make

\footnotetext{
${ }^{4}$ In his classic work, Clark (2011) connected the idea of a distributed and extended cognition to the notion of epistemic artifact, in other words, structural entities that organize the way in which we obtain, process and communicate beliefs.
}

(C) Cristián Santibáñez. Informal Logic, Vol. 38, No. 4 (2018), pp. 531-549. 
our predictions come true. ${ }^{5}$ I believe that these actions that make predictions become a reality are, in fact, associated with the notion of collective, or interpersonal, distributed cognition. This is in line with Huebner's idea of collective minds.

An example of the collective mind's functioning will be of help to grasp the notion. Autobiographical narrative is, paradigmatically, a case of distributed cognition - if you do not believe it, ask your psychoanalyst! - since we remember, or reconstruct, our life events with the help of others. It is what Sutton (2006) calls the transactional nature of collaborative remembering. Huebner describes it in a very elegant way, pointing out that given the intimate relationship between the significance of memory, attention, and power, it is safe to assume that there will be a good number of situations and cases where my autobiographical events will be saved internally by the people that surround me, more so than by myself. The autobiographical collective memories are often produced when a person's expression of a memory triggers another person's memory related to the same event. Huebner (2015: 238) reminds us that since memory is fragile, in many cases, we encode just enough information to allow us to reconstruct past events based on the general strategy of contrafactual reasoning. The same occurs when the cognitive process of remembering my biographical events is in the mind of others who construct, by means of a single impulse, my identity - or part of it - , or the group's identity by means of the memories of those who are part of that group.

In my opinion, the critical or dialectical potential that visual argumentation has (advertising campaigns are in media circulation for months or years, political campaigns are remembered and

\footnotetext{
${ }^{5}$ Clark is specifically thinking about motor and perceptive matters. But these dimensions help to think about cognition's superior levels, such as the symbolic and communicative dimension. Clark says that: "'Active inference'... then names the combined mechanism by which perceptual and motor systems conspire to reduce prediction error using the twin strategies of altering predictions to fit the world, and altering the world to fit the predictions. This general schema may also - perhaps more transparently - be labelled 'actionoriented predictive processing'... In the case of motor behaviours, the key driving predictions now have a subjunctive flavour. They are... predictions of the proprioceptive patterns that would ensue were the action to be performed. 'Proprioception' names the inner sense that informs us about the relative locations of our bodily parts and the forces and efforts that are being applied." (2016: 122)
}

(C) Cristián Santibáñez. Informal Logic, Vol. 38, No. 4 (2018), pp. 531-549. 
reused for attacking or defending past positions), is typically a distributed and extended cognitive strategy in the sense that they contain the arguments I, my community, and others can potentially use for new controversial challenges. Furthermore, they reduce the cognitive cost of processing the information in controversial settings - in fact, they replace the task of memorizing and recovering the process; they distribute, recreate, and generationally transfer the collective beliefs and the intentionality contained in them - the endoxon graphically recovered by the Lugano School; and they contain predictions about collective tendencies at the same time that they provoke or guide collective, or interpersonal, actions. It is not only a certain argument's contents that can be found in visual argumentation, it is, in fact, the potential argument as a whole that I can use, and that is totally processed and navigated in the environment. Individuals rely on-and perhaps even trustvisual argumentation to locate arguments beyond their biological boundaries, and through this action become dependent on it.

Visual argumentation expressions are also models of collective epistemic artifacts since they have enough flexibility to be used according to multiple cultural parameters, while they serve to construct belief hierarchies (endoxon is an example). The example of visual argumentation used previously provides a possible justification for that. The arguments exposed in each argumentativeoriented visual image help me when I do not have an appropriate argument at hand. As a matter of fact, in many cases, the arguments that specific visual argumentation campaigns propagate are the only ones that I could have, since on many occasions we do not have a fully elaborated opinion on those matters. Here lies, I think, the reason why distributed and extended cognition is such a powerful and beneficial evolutionary stable strategy for human cognitive functioning. It reveals our weaknesses and strengths: the capacity to take out of our biological limits our creations and, at the same, a heavy dependence on this cognitive processing.

To be sure, images have lexical deficits, there is always a semantic investment to be made by recipients. Images have syntactic gaps: the absence of connectors, for example. Sometimes images lack metalanguage and explicit markers, that is, the support of the 
linguistic component is always needed, no matter how small, to trigger the argumentative activity. As Adam and Bonhomme (2012) rightly emphasize, images become premises, or reasons, by means of the association between icon and topoi, that is, from the relationship between the image's materiality (geometry, coloration, texture), and the stereotyped units of common beliefs (ideology, endoxon). Since this association can shift easily, argumentation via an image (or with an image) is always probabilistic. To reduce that mobility, recipients develop a series of - automatic - calculations: referential (to whom, when, where), topical (which underlying concepts does the image convey?), axiological (aesthetic and ethical valorizations).

In order to know in more detail the ways in which images used argumentatively are forms of extended cognition, more empirical and experimental research has to be done. But in argumentation theory we should not avoid the challenge of understanding the argumentative competence and practice as part, or manifestation, of a broader human cognitive architecture to deal with both the environment and their fellows.

Acknowledgments: The author would like to thank the reviewers for their sharp comments that made this work clearer.

\section{References}

Adam, Jean-Michael and Marc Bonhomme. 2012. L'argumentation publicitaire. Rhétorique de l'éloge et la persuasion. Paris: Armand Colin.

Clark, Andy. 2011. Supersizing the Mind. Embodiment, Action, and Cognitive Extension. New York: Oxford.

Clark, Andy. 2016. Surfing Uncertainty. Prediction, Action and the Embodied Mind. New York: Oxford.

Clark, Andy and David Chalmers. 1998. The extended mind. Analysis 58: 7-19.

Corballis, Michael. 2018. The Truth about Language: What It Is and Where It Came From. Chicago: University of Chicago Press. 


\section{Santibáñez}

Dupuy, Jena-Pierre. 2000. The Mechanization of the Mind: On the Origins of Cognitive Science. Princeton: Princeton University Press.

Eemeren, Frans van and Rob Grootendorst. 1992. Argumentation, Communication, and Fallacies. A Pragma-dialectical Perspective. Hillsdale, NJ: Lawrence Erlbaum Associates.

Gigerenzer, Gerd. 2007. Gut Feelings: The intelligence of the unconscious. New York: Viking Press.

Groarke, Leo. 2009. Five Theses on Toulmin and Visual Argument. In Pondering on problems of argumentation. Twenty Essays on Theoretical Issues, eds. Frans van Eemeren and Bart Garssen, 229-242. Dordrecht: Springer.

Hegarty, Mary and Andrew Stull. 2012. Visuospatial Thinking. In The Oxford Handbook of Thinking and Reasoning eds. Keith Holyoak \& Robert Morrison, 606-630. New York: Oxford.

Holland, James and Edwin Huchins. 2009. Opportunities and Challenges for Augmented Environments: A Distributed Cognition Perspective. In Designing User Friendly Augmented Work Environments: From Meeting Rooms to Digital Collaborative Spaces, eds. S. Lahlou, 237259. London: Springer-Verlag.

Huebner, Bryce. 2015. Macrocognition. A Theory of Distributed Minds and Collective Intentionality. New York: Oxford.

Hutchins, Edwin. 1995. Cognition in the Wild. Cambridge, Mass.: MIT Press.

Hutchins, Edwin. 2005. Material anchors for conceptual blends. Journal of Pragmatics 37: 1555-1577.

Hutchins, Edwin. 2008. The role of cultural practices in the emergence of modern human intelligence. Philosophical Transactions of the Royal Society Series B 363: 2011-2019.

Hutchins, Edwin. 2010. Cognitive ecology. Topics in Cognitive Science 2: $705-715$.

Johnson-Laird, Philip. 1983. Mental Models: Toward a Cognitive Science of Language, Inference and Consciousness. Cambridge, Mass.: Harvard University Press.

Kirsh, David. 1995. The intelligent use of space. Artificial Intelligence 73: 31-68. 
Kirsh, David. 1996. Adapting the environment instead of oneself." Adaptive Behavior 4: 415-452.

Kjeldsen, Jens. 2015. Where is Visual Argument? In Reflections on Theoretical Issues in Argumentation Theory, eds. Frans van Eemeren and Bart Garssen, 107-120. Dordrecht: Springer.

Malafouris, Lambros. 2013. How Things Shape the Mind. A Theory of Material Engagement. Cambridge, MA.: The MIT Press.

Marraud, Hubert. 2016. The role of Ostension in Visual Argumentation. Cogency, 8(1): 21-42.

Osbeck, Lisa and Nancy Nersessian. 2014. Situating distributed cognition Philosophical Psychology 27: 82-97.

Pachur, Thorsten, Peter Todd, Gerd Gigerenzer, Lael Schooler and Daniel Goldstein. 2012. When is the recognition heuristic an adaptive tool? In Ecological Rationality. Intelligence in the World eds. Peter Todd, Gerd Gigerenzer and The ABC Research Group, 113-143. New York: Oxford.

Patterson, Steven. 2010. "A picture held us Captive": The later Wittgenstein on visual argumentation. Cogency 2(1): 105-134.

Pohl, Rüdiger. 2012. Cognitive Illusions. A Handbook on fallacies and biases thinking, judgement and memory. New York: Psychology Press.

Rigotti, Eddo and Sara Greco. 2010. Comparing the Argumentum Model of Topics to Other Contemporary Approaches to Argument Schemes: The Procedural and Material Components. Argumentation 24 (4): 489512.

Rips, Lance. 1994. The Psychology of Proof. Deductive Reasoning in Human Thinking. Cambridge, Mass.: MIT Press.

Rupert, Robert. 2004. Challenges to the hypothesis of extended cognition. Journal of Philosophy 101 (8): 389-428.

Sterenly, Kim. 2012. The Evolve Apprentice: How Evolution Made Humans Unique. Cambridge, Mass.: The MIT Press.

Sutton, John. 2006. Distributed cognition: domains and dimensions. Pragmatics and Cognition 14(2): 235-247. 


\section{Santibáñez}

Toulmin, Stephen. 1958. The Uses of Argument. Cambridge: Cambridge University Press.

Tversky, Barbara. 2011. Visualizing thought. Topics in Cognitive Science 3(3): 499-535.

Wittgenstein, Ludwig. 2001. Philosophical Investigations. G.E.M. Anscombe (Translator.), 50th Anniversary Commemorative Edition. London: Blackwell Publishing, Inc. 